\title{
Article \\ FLIM-Based Intracellular and Extracellular pH Measurements Using Genetically Encoded pH Sensor
}

\author{
Alexander S. Goryashchenko ${ }^{1, *(D)}$, Alexey A. Pakhomov ${ }^{1,2}$, Anastasia V. Ryabova ${ }^{3} \mathbb{D}^{\circ}$, Igor D. Romanishkin ${ }^{3} \mathbb{C D}$, \\ Eugene G. Maksimov ${ }^{4}\left(\mathbb{D}\right.$, Alexander N. Orsa ${ }^{1}$, Oxana V. Serova ${ }^{1}{ }^{(D}$, Andrey A. Mozhaev $\left.{ }^{1,5}{ }^{(}\right)$, \\ Margarita A. Maksimova ${ }^{1,2}$, Vladimir I. Martynov ${ }^{1}$, Alexander G. Petrenko ${ }^{1}$ and Igor E. Deyev ${ }^{1,6} \mathbb{D}$ \\ 1 Shemyakin-Ovchinnikov Institute of Bioorganic Chemistry of the RAS, 117997 Moscow, Russia; \\ alpah@mail.ru (A.A.P.); Saniaorsa@gmail.com (A.N.O.); oxana.serova@gmail.com (O.V.S.); \\ a.a.mozhaev@gmail.com (A.A.M.); ritamax2000@yandex.ru (M.A.M.); vimart@list.ru (V.I.M.); \\ petrenkoag@gmail.com (A.G.P.); deyevie@gmail.com (I.E.D.) \\ 2 A. N. Nesmeyanov Institute of Organoelement Compounds of the RAS, 119991 Moscow, Russia \\ 3 Prokhorov General Physics Institute of the RAS, 119991 Moscow, Russia; nastya.ryabova@gmail.com (A.V.R.); \\ Igor.Romanishkin@gmail.com (I.D.R.) \\ 4 Department of Biology, M.V. Lomonosov Moscow State University, 119234 Moscow, Russia; \\ emaksimoff@yandex.ru \\ 5 A.V. Shubnikov Institute of Crystallography of Federal Scientific Research Centre \\ "Crystallography and Photonics" of Russian Academy of Sciences, 119991 Moscow, Russia \\ 6 Sirius University of Science and Technology, 354340 Sochi, Russia \\ * Correspondence: asgoryash@ibch.ru
}

Citation: Goryashchenko, A.S.; Pakhomov, A.A.; Ryabova, A.V.; Romanishkin, I.D.; Maksimov, E.G.; Orsa, A.N.; Serova, O.V.; Mozhaev, A.A.; Maksimova, M.A.; Martynov, V.I.; et al. FLIM-Based Intracellular and Extracellular $\mathrm{pH}$ Measurements Using Genetically Encoded pH Sensor. Biosensors 2021, 11, 340. https://doi.org/10.3390/bios11090340

Received: 9 August 2021

Accepted: 10 September 2021

Published: 15 September 2021

Publisher's Note: MDPI stays neutral with regard to jurisdictional claims in published maps and institutional affiliations.

Copyright: (c) 2021 by the authors. Licensee MDPI, Basel, Switzerland. This article is an open access article distributed under the terms and conditions of the Creative Commons Attribution (CC BY) license (https:// creativecommons.org/licenses/by/ $4.0 /)$.

\begin{abstract}
The determination of $\mathrm{pH}$ in live cells and tissues is of high importance in physiology and cell biology. In this report, we outline the process of the creation of SypHerExtra, a genetically encoded fluorescent sensor that is capable of measuring extracellular media $\mathrm{pH}$ in a mildly alkaline range. SypHerExtra is a protein created by fusing the previously described $\mathrm{pH}$ sensor SypHer3s with the neurexin transmembrane domain that targets its expression to the cytoplasmic membrane. We showed that with excitation at $445 \mathrm{~nm}$, the fluorescence lifetime of both SypHer3s and SypHerExtra strongly depend on $\mathrm{pH}$. Using FLIM microscopy in live eukaryotic cells, we demonstrated that SypHerExtra can be successfully used to determine extracellular $\mathrm{pH}$, while SypHer3s can be applied to measure intracellular $\mathrm{pH}$. Thus, these two sensors are suitable for quantitative measurements using the FLIM method, to determine intracellular and extracellular $\mathrm{pH}$ in a range from $\mathrm{pH} 7.5$ to 9.5 in different biological systems.
\end{abstract}

Keywords: GFP; SypHer3s; SypHerExtra; fluorescent proteins; $\mathrm{pH}$; $\mathrm{pH}$ sensor; intracellular $\mathrm{pH}$; extracellular $\mathrm{pH}$; FLIM

\section{Introduction}

The measurement of $\mathrm{pH}$ in an organism or in cellular compartments has various applications in cell biology and medicine. In live systems, the acid-base balance controls many biochemical processes, and $\mathrm{pH}$ disturbances largely affect cell growth, cell division, and its functions [1]. $\mathrm{pH}$ dysregulation is associated with multiple human diseases, such as kidney failure, Alzheimer's disease, and cancer [2-5]. It is also known that even small $\mathrm{pH}$ disturbances can alter prohormone processing [6,7]. Thus, the task of accurate $\mathrm{pH}$ measurement in living systems, although technically quite challenging, is extremely important, and over the past twenty years, the development of fluorescent probes was aimed to solve this problem.

The diversity of synthetic and genetically encoded fluorescent sensors has increased in recent years, and thus has given us powerful tools for determining $\mathrm{pH}$ in living cells [8]. Genetically encoded sensors have many benefits and are potentially suitable for targeting tissues and cells and for being expressed in transgenic animals $[9,10]$. Most of the currently 
available $\mathrm{pH}$ sensors [11,12] have a $\mathrm{pKa}$ that lies in the acidic to neutral $\mathrm{pH}$ range, and there are only a few that have an alkaline $\mathrm{pKa}$. The best sensors out of those with an alkaline $\mathrm{pKa}$ are the ratiometric sensors deGFP1 (pKa 8.0) [13], SypHer2 (pKa 8.1) [14], and SypHer3s (pKa 7.8) [15]. All of them were successfully used to measure intracellular $\mathrm{pH}$.

SypHer3s is a genetically encoded fluorescent $\mathrm{pH}$ probe with a ratiometric readout from $\mathrm{pH} 5.5$ to 10.0, and an improved brightness compared to its predecessors SypHer and SypHer2 [15]. Originally, SypHer was generated by introducing a C199S mutation to the hydrogen peroxide sensor HyPer [16]. This mutation makes HyPer insensitive to hydrogen peroxide while preserving its sensitivity to $\mathrm{pH}$ variations.

Fluorescent $\mathrm{pH}$ sensors have a ratiometric or intensiometric readout. Ratiometric readout means that the sensor's analytical signal is the ratio of its fluorescence intensity at different wavelengths. Such readout provides quantitative measurements and has no potential artifacts that might arise due to cell movement or changes in the cell's shape. While a ratiometric readout is good enough in the case of in cellulo measurements, the different depth of wavelength penetration through the tissues of living organisms may result in incorrect $\mathrm{pH}$ measurements inside the organs or tissues. To solve this problem, the fluorescence lifetime imaging microscopy (FLIM) technique could be used for the readout of the probe response $[17,18]$. In this study, we created the fluorescent sensor SypHerExtra, which is capable of measuring extracellular $\mathrm{pH}$ in a mildly alkaline range, and showed that it is suitable for the quantitative monitoring of extracellular $\mathrm{pH}$ by FLIM.

\section{Materials and Methods}

\subsection{Plasmid Construction}

Chimera construct pST-SH3-Nx based on pSecTag 2B vector with IgK leader peptide, which was fused with SypHer3 and rat neurexin transmembrane part, was obtained using PCR cloning strategy. Eukaryotic pC1-SypHer3s vector for cytoplasmic SypHer3s expression was kindly provided by Y.G. Ermakova, IBCh RAS. This vector was used as a template for PCR with $5^{\prime}$-AAAGGATCCATGTCCGGACCGCTGCACATT- $3^{\prime}$ and $5^{\prime}$ TTTGAATTCCGCTAACCGCCTGTTTTAAAACTTTATC-3' primers to produce SypHer3s cDNA. This coding sequence was cloned into the pSecTag vector using EcoRI and BamHI restriction sites. As a transmembrane linker that connects SypHer3s to a cell membrane we used a region of $\alpha$-neurexin protein containing 146 amino acids from its extracellular part, 21 amino acids from the transmembrane domain and 35 amino acids from the cytoplasmic domain. cDNA of this linker was produced by PCR with pcDNA-Nx(SS6-)-HA plasmid [19] as a template, forward primer $5^{\prime}$-GCCGAATTCAGAAAGTTCTGAATATGGCGGCAGA-3' and reverse primer $5^{\prime}$-GCGCTCGAGGACATAATACTCCTTATCCTTGTTC-3'. Obtained linker domain cDNA was inserted into the pSecTag-SypHer3s vector using EcoRI and XhoI restriction sites. The structure of the obtained vector was confirmed by sequencing.

\subsection{Determination of the SypHerExtra Sensor Localization}

To be sure that obtained SypHerExtra sensor has membrane localization, immunocytochemistry technique was carried out. Twelve millimeter P231.1 cover glasses (MenzelGläser, Braunschweig, Germany) were placed into a 24-well culture dish and treated with poly-L-lysine (Sigma-Aldrich, St. Louis, MO, USA). Then HEK293 and HeLa cells were seeded onto this culture dish and grown in Dulbecco's modified Eagle medium (DMEM) supplemented with 10\% fetal bovine serum (Hyclone, Logan, UT, USA), $1 \%$ penicillin/streptomycin, and $2 \mathrm{mM}$ L-glutamine. Transfection with pST-SH3-Nx plasmid was carried out using Unifectin-56 (Unifect Group, Moscow, Russia) reagent, according to manufacturer's protocol. Two days after transfection, the cells were washed with phosphate-buffered saline (PBS) and fixed with a mixture of methanol/acetone 1:1 v/v for $20 \mathrm{~min}$ at $-20^{\circ} \mathrm{C}$. To prevent non-specific antibody adsorption, cells were incubated in PBS containing $2 \%$ bovine serum albumin for $3 \mathrm{~h}$ at room temperature. Then overnight incubation at $4{ }^{\circ} \mathrm{C}$ with anti-GFP primary antibodies (Evrogen, Moscow, Russia) dissolved in PBS at a ratio of 1:5000 was carried out. Unbound antibodies were washed off with PBS 
three times for $7 \mathrm{~min}$, and then secondary goat antibodies conjugated with Cy3 against rabbit IgG were added (Jackson ImmunoResearch, Cambridge House, St. Thomas' Place, Cambridgeshire, UK), dissolved in PBS at a ratio of 1:5000. After $1 \mathrm{~h}$ incubation at room temperature, unbound antibodies were washed off with PBS three times for $7 \mathrm{~min}$ followed by fixation of the cells on the cover slides using Glycergel mounting medium (Dako, Glostrup, Denmark).

We also studied whether the SypHerExtra was endocytosed. HEK293 cells were co-transfected with pST-SH3-Nx and pmKate2-endo (Evrogen, Moscow, Russia) vectors and fixed on the cover slides using the protocol mentioned above.

Cell imaging was carried out using Nikon Eclipse TE2000-E confocal microscope equipped with a 60x oil immersion objective. For SypHerExtra visualization, $488 \mathrm{~nm}$ laser excitation and 515/10 nm emission filter were used, while for Cy3-labeled antibodies and mKate2 visualization, $515 \mathrm{~nm}$ laser excitation and 650/30 nm emission filter were used.

\subsection{Protein Preparation and UV/VIS Spectrophotometry}

For protein expression, the cDNA encoding SypHer3s was cloned into the pQE-30 vector (providing N-terminal His-tag). E. coli (BL21(DE3) strain) cells were then transformed with this vector, followed by protein production in bacteria. The recombinant protein was further purified from the cells by immobilized metal affinity chromatography on Ni-NTA resin (Qiagen, Hilden, Germany) according to the manufacturer's protocol and then dialyzed to the PBS. Absorption spectra of SypHer3s at different $\mathrm{pH}$ were collected in buffer STPCA (100 mM NaCl, $12.5 \mathrm{mM}$ Tris, $12.5 \mathrm{mM}$ sodium phosphate, $12.5 \mathrm{mM}$ sodium acetate, $12.5 \mathrm{mM}$ CAPS, $\mathrm{pH}$ 6.9) and titrated to desirable $\mathrm{pH}$. Cary 50 Bio UV/VIS spectrophotometer (Varian, Palo Alto, CA, USA) was used to measure absorption spectra.

\subsection{In Vitro Fluorescence Lifetime Measurements}

In order to determine the relationship between the $\mathrm{pH}$ of a solution and the lifetime of SypHer3s, experiments were conducted on a series of buffers with $\mathrm{pH}$ values validated by standard methods.

Purified SypHer3s samples were transferred into $500 \mathrm{mM}$ Tris- $\mathrm{HCl}$ buffer with $\mathrm{pH}$ ranging from 6.5 to 9.5 with 0.5 increments, and then fluorescence lifetime measurements were performed using time-correlated single photon counting (TCSPC) system SimpleTau 140 (Becker\&Hickl, Berlin, Germany) with $405 \mathrm{~nm}, 445 \mathrm{~nm}$ and $510 \mathrm{~nm}$ excitation lasers. Longpass filters (Thorlabs, Newton, NJ, USA) were used to filter out the excitation light. A ML-44 monochromator additionally filtered the emission (Solar, Minsk, Belarus). Fluorescence decay kinetics were analyzed with Becker\&Hickl SPCImage software. Considering that at different pHs SypHer3s might be in two distinct conformational states, fluorescence decay kinetics were approximated using two-exponential model, and average fluorescence lifetimes were calculated.

\subsection{Cell Lines and Transfection}

HEK 293 cells were grown on FluoroDish cell culture dishes with a 0.16-mm-thick glass bottom (WPI, Sarasota, FL, USA) in DMEM supplemented with 10\% fetal bovine serum (Hyclone, Logan, UT, USA), 1\% penicillin/streptomycin, and $2 \mathrm{mM} \mathrm{L-glutamine} \mathrm{and}$ transfected with pC1-SypHer3s (for cytoplasmic SypHer3s) or pST-SH3-Nx (for SypHerExtra) plasmid using Unifectin-56 (Unifect Group, Moscow, Russia) reagent, according to manufacturer's protocol.

\subsection{FLIM Measurements}

To vary the intracellular $\mathrm{pH}$ of the HEK293 cells expressing cytoplasmic SypHer3s, nigericin ionophore was used. Two days after the transfection of the cells, the culture medium was replaced with $50 \mathrm{mM}$ Tris- $\mathrm{HCl}$ buffers with $\mathrm{pH}$ from 6.5 to 9.5 containing $105 \mathrm{mM} \mathrm{KCl}, 1 \mathrm{mM} \mathrm{MgCl} 2$ and $10 \mu \mathrm{M}$ nigericin according to [20] and, after $5 \mathrm{~min}$ of incubation, FLIM images of cells were obtained. 
Fluorescence lifetime measurements of the HEK293 cells expressing cytoplasmic SypHer3s were performed using Zeiss LSM-710 NLO confocal/multiphoton microscopy system consisting of the inverted Axio Observer (Zeiss, Jena, Germany) microscope, the femtosecond laser Chameleon Ultra II (80 MHz, 140 fs, tunable in 690-1060 nm, Coherent Inc., Santa Clara, CA, USA) used for excitation, and the HPM-100-07 hybrid GaAsP photodetector (Becker\&Hickl, Berlin, Germany) connected to a non-descanned (NDD) port of the microscope. Appropriate dichroics and band-pass filters were used to collect SypHer3 fluorescence. The detection channel also contained a $760 \mathrm{~nm}$ short-pass filter (Zeiss, Germany) in the beam path to avoid the background excitation. SPC-150 TCSPC module (Becker\&Hickl, Berlin, Germany) was synchronized with the laser pulses and the Zeiss LSM-710 scan head signals to collect the time-resolved fluorescence in TCSPC mode using SPCM acquisition software. SypHer3s fluorescence was excited at $890 \mathrm{~nm}$ laser wavelength through two-photon absorption. A 63x oil Plan-Apochromat NA 1.4 objective was used to acquire the FLIM images that consisted of $512 \times 512$ pixels with 1024 time channels. To compare different decay curves, we calculated the amplitude-weighted average fluorescence lifetime for each FLIM image. Average fluorescence lifetimes were calculated as follows: for each FLIM image, the lifetimes were calculated using two-exponential model (one for each chromophore state-neutral and anionic, each with its own lifetime) and Binning 3, then separate cells were chosen using area ROI and their lifetime distribution histograms were exported to the Origin Pro 9.1 software (OriginLab, Northampton, MA, USA). Next, nonlinear curve fit of the histograms was performed using GaussAmp model, and lifetimes corresponding to the histograms' peaks were used as lifetimes of different cells on the frame. Based on these lifetime values, average fluorescence lifetime was calculated for each $\mathrm{pH}$.

For SypHerExtra, the measurement protocol was the same except for the nigericin addition. To analyze obtained FLIM images, membrane regions of the cells were selected using linear ROI, and the average fluorescence lifetime for each $\mathrm{pH}$ was calculated as mentioned above.

\section{Results}

First, we generated a genetically encoded fluorescent sensor with membrane anchoring extracellular expression. For this, we made a chimera construct based on the pSecTag 2B vector with an IgK leader peptide, which was fused with SypHer3s and the neurexin transmembrane part for expression on the extracellular side of the cytoplasmic membrane (Figure 1A). We named it SypHerExtra. Transfection of HEK 293 or HeLa cells with this construct showed the expected localization of this chimera protein on the cell membrane (Figures 1B and S1).

A

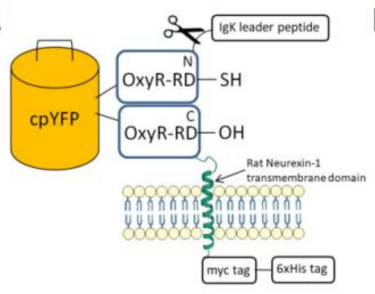

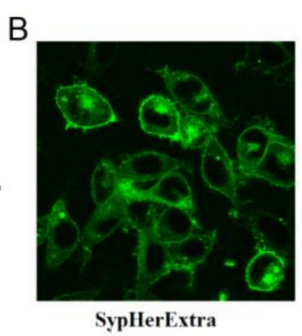

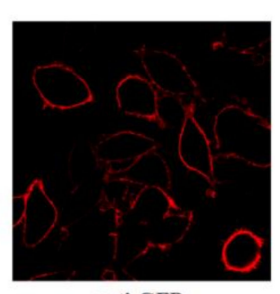

anti-GFP



merge

Figure 1. (A) Schematic representation of a genetically encoded construct SypHerExtra with extracellular expression and membrane anchoring; (B) fluorescent images of the fixed HEK293 cells expressing extracellular membrane-anchored SypHerExtra sensor (left) stained with anti-GFP antibodies (center). The merged image (right) indicates membrane-anchored SypHerExtra.

In addition, we have studied the possible colocalization of SypHerExtra with endosomes. To visualize endosomes, we used the pmKate2-endo vector (Evrogen, Moscow, Russia) that encodes the far-red fluorescent protein mKate2, targeted to endosomes by human RhoB GTPase fused to the mKate2 C-terminus [21]. The co-transfection of HEK293 cells 
with pST-SH3-Nx and pmKate2-endo plasmids revealed that SypHerExtra colocalizates with endosomes (Figure 2). This would be a great opportunity to measure endo-lysosomal $\mathrm{pH}$ using the SypHerExtra sensor, but with a $\mathrm{pKa}$ of 7.8 [15], it is sensitive to $\mathrm{pH}$ values from neutral to mildly alkaline, while endosomal $\mathrm{pH}$ varies from 4.5 to 6.5 [22]. Nevertheless, the replacement of alkali-sensitive SypHer3s protein with an acid-sensitive one in the SypHerExtra construction could help to overcome this limitation.

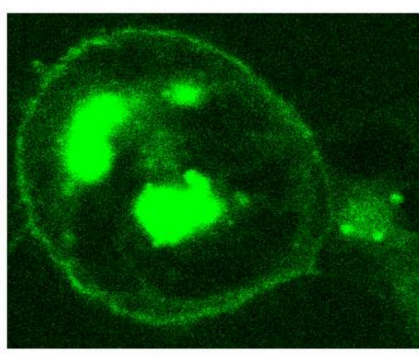

SypHerExtra

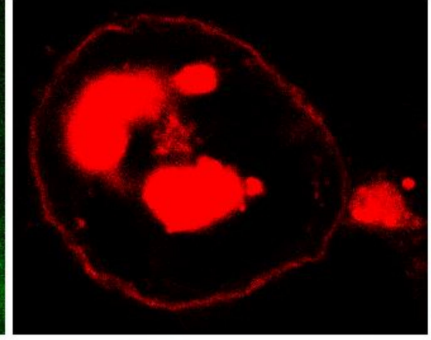

mKate2-tagged endosomes

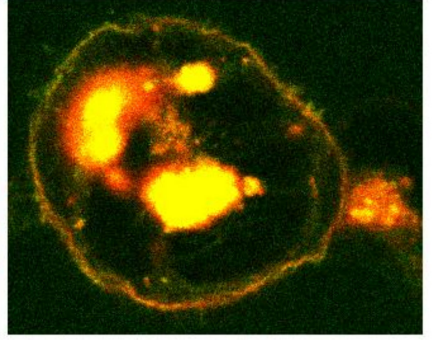

Merge

Figure 2. Fluorescent images of the fixed HEK293 cells expressing extracellular membrane-anchored SypHerExtra sensor (left) and mKate2 fluorescent protein targeted to endosomes (center). The merged image (right) indicates SypHerExtra colocalizated in endosomes.

Then, we tested the applicability of SypHer3s as an FLIM pH sensor, by analyzing the $\mathrm{pH}$ dependence of its fluorescence lifetime, using the TCSPC (time-correlated single photon counting) method in the cuvette. SypHer3s has two peaks of light absorption in the visible region, at 410 and $500 \mathrm{~nm}$, which correspond to neutral and anionic states of a chromophore, respectively (Figure 3A) [15].


Figure 3. (A) Absorbance spectra of the SypHer3s at different $\mathrm{pH}$; (B) $\mathrm{pH}$ dependence of the SypHer3s fluorescence lifetime in vitro using different excitation wavelengths- $510 \mathrm{~nm}$ (black curve), $445 \mathrm{~nm}$ (red curve) and $405 \mathrm{~nm}$ (blue curve).

Therefore, we used pulsed 405 and $510 \mathrm{~nm}$ lasers as a source of excitation light and measured the SypHer3s fluorescence lifetime at a $\mathrm{pH}$ ranging from 6.5 to 9.5. The detected fluorescence lifetimes at 405 and $510 \mathrm{~nm}$ excitation were almost independent of $\mathrm{pH}$, and were found to be approximately $2.8 \mathrm{~ns}$ for the anionic chromophore ( $510 \mathrm{~nm}$ excitation) and $1.0 \mathrm{~ns}$ for the protonated chromophore (405 $\mathrm{nm}$ excitation) (Figure 3B). A small increase in the lifetime at high $\mathrm{pH}$, at $405 \mathrm{~nm}$ excitation, is probably due to the absorption of an anionic chromophore at the tail of the main absorption peak of $500 \mathrm{~nm}$. Next, we used a $445 \mathrm{~nm}$ pulsed laser that should effectively excite both the anionic and protonated forms of the chromophore (Figure 3B). As expected, the fluorescence lifetime increased with increasing $\mathrm{pH}$. Thus, in acidic conditions, due to the presence of a mainly protonated chromophore, the lifetime was approximately $1.2 \mathrm{~ns}$, while, in an alkaline environment, where the anionic form of the chromophore dominates, the fluorescence lifetime increased to 2.4 ns. So, it is fundamentally possible to estimate $\mathrm{pH}$ by measuring the fluorescence lifetime of the SypHer3s sensor using the $445 \mathrm{~nm}$ or a similar laser as a source of excitation light. 
To test SypHer3s in cellulo, we performed calibration experiments in HEK 293 cells, by treating them with nigericin ionophore and using a set of Tris- $\mathrm{HCl}$ buffers with a $\mathrm{pH}$ from 6.5 to 9.5. For these experiments, we used two-photon excitation at $890 \mathrm{~nm}$, which should excite both the neutral and anionic forms of the fluorophore. We transfected HEK 293 cells with a construct that encodes cytoplasmic SypHer3s protein with eukaryotic expression, and treated these cells with antibiotic nigericin, which acts as a $\mathrm{H}^{+}$and $\mathrm{K}^{+}$ionophore, and therefore equalizes the $\mathrm{pH}$ value inside and outside the cell $[23,24]$. Then, we measured the fluorescence lifetime under different pHs (Figures $4 \mathrm{~A}$ and S3). The exposure of cytoplasmic SypHer3s to different $\mathrm{pHs}$ also shows the correlation between fluorescence lifetime and $\mathrm{pH}$ (Figure 4).
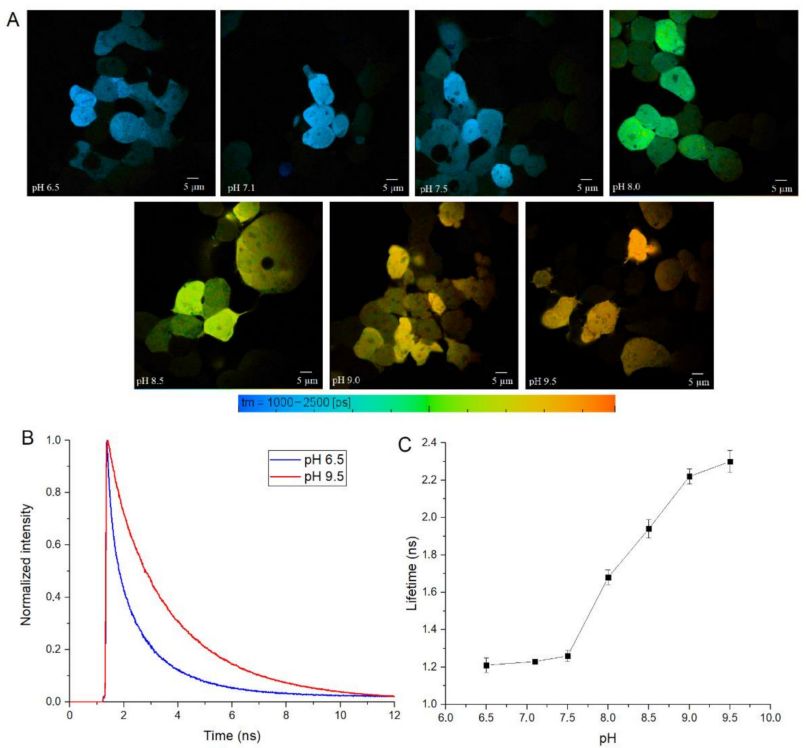

Figure 4. (A) FLIM images of the nigericin-treated HEK293 cells expressing cytoplasmic SypHer3s sensor at different $\mathrm{pH}$ values varying from 6.5 (upper-left image) to 9.5 (lower-right image); (B) fluorescence decay kinetics of the cytoplasmic SypHer3s in HEK293 cells treated with nigericin at pH 6.5 (blue curve) and $\mathrm{pH} 9.5$ (red curve); (C) the $\mathrm{pH}$ dependence of the cytoplasmic SypHer3s fluorescence lifetime in HEK293 cells treated with nigericin. Values are the average of $\geq 4$ different cells \pm S.D.

Finally, we tested SypHerExtra for measuring extracellular $\mathrm{pH}$ bound to the membrane in live cells. HEK 293 cells were transfected with this construct, and treated with Tris$\mathrm{HCl}$ buffer with $\mathrm{pH}$ ranging from 6.5 to 9.5 (Figures 5A and S4). The detection of the fluorescence lifetime of SypHerExtra by FLIM technique shows changes in the fluorescence lifetime, as in previous experiments (Figure 5B,C). 




Figure 5. (A) FLIM images of the HEK293 cells expressing SypHerExtra sensor at different pH values from 6.5 (upper-left image) to 9.5 (lower-right image); (B) fluorescence decay kinetics of SypHerExtra in HEK293 cells at pH 6.5 (blue curve) and pH 9.5 (red curve); (C) the pH dependence of SypHerExtra fluorescence lifetime in HEK293 cells. Values are the average of $\geq 6$ different cells \pm S.D, except for $\mathrm{pH}$ 9.0, where only three cells were detected.

\section{Discussion}

Measuring $\mathrm{pH}$ in complex biological systems in vivo represents a significant biological challenge, especially when it comes to small animals, such as mice. $\mathrm{pH}$-sensitive probes must not interfere with the natural environment and should be small enough to allow an accurate analysis of local $\mathrm{pH}$ variations. Genetically encoded fluorescent $\mathrm{pH}$ sensors are one of the best choices to achieve this goal [11].

Although the general paradigm is that the $\mathrm{pH}$ of blood and other extracorporeal liquids is close to neutral, there are examples of significant $\mathrm{pH}$ shifts in visceral organs, especially those that are involved in food digestion [25]. Also, a lot of experimental data have been accumulated that suggest the existence of $\mathrm{pH}$ local shifts in the nervous system [26].

Recently, we demonstrated that at least three receptor tyrosine kinases-insulin receptor-related receptor (IRR), ErbB2, and c-Met - can be activated by incubation with mildly alkaline extracellular medium with $\mathrm{pH}>8.0$ [27-30]. IRR is a receptor tyrosine kinase of the insulin receptor family, which can be activated merely by an increase in the extracellular $\mathrm{pH}(\mathrm{pH}>7.9)$, and in vivo experiments in knockout mice revealed the role of IRR as a regulator of bicarbonate excretion in the kidneys.

Since the known genetically encoded $\mathrm{pH}$ sensors are designed to measure intracellular $\mathrm{pH}$, and most of them react to a mildly acidic environment, we aimed to generate a genetically encoded ratiometric $\mathrm{pH}$ sensor that is suitable for extracellular $\mathrm{pH}$ measurements in the $\mathrm{pH}$ range from 7.4 to 9.0 , which could be used in poorly transparent organs, such as the kidneys or stomach.

To achieve this goal, we created the SypHerExtra sensor, on the basis of the recently described fluorescent $\mathrm{pH}$ sensor Sypher3s [15], fused with a signal peptide and the transmembrane region of neurexin I, which is a cell adhesion receptor of the brain [31]. We showed that SypHerExtra is transported to the cytoplasmic membrane, where it can sense mildly alkaline media. It should be noted that we used transient cell transfection; therefore, the expression of both SypHer3s and SypHerExtra proteins varies from cell to cell. According to our data, all the cells that express SypHerExtra responded to the change in $\mathrm{pH}$ of the media, but the intensity of the fluorescence signal that we measured depends on the transfection efficiency. 
Using FLIM, instead of intensity-based measurements, allowed us to minimize the spectral bleed-through of two fluorescent forms of SypHer3s and so-called inner filter effects, which are absorption and scattering events that affect the fluorescence intensity, especially in non-transparent tissues and organs [17].

In addition, we have successfully used the two-photon excitation method, using a pulsed laser, with a wavelength of $890 \mathrm{~nm}$, as the source of excitation light. Compared with single-photon excitation, this method has a greater signal penetration depth; according to various estimates, it ranges from 0.5 to $1.6 \mathrm{~mm}$ [32-34]. In addition, long-wave excitation light has less scattering, lower phototoxicity, and reduced photobleaching of fluorophores due to its lower photon energy. Finally, since the required energy of excitation light is achieved in a very small focal volume, there is no fluorescent signal in the tissues located above and below the focal plane, which allows increased resolution compared to singlephoton confocal microscopy [35].

It is interesting to note that SypHerExtra has a shorter fluorescence lifetime at $\mathrm{pH} 9.5$ than recombinant or cytoplasmic SypHer3s. To be precise, the lifetime of cytoplasmic SypHer3s changes from 1.2 ns at $\mathrm{pH} 6.5$ to 2.4 ns at pH 9.5, while SypHerExtra lifetimes are about $1.4 \mathrm{~ns}$ at $\mathrm{pH} 6.5$ and $1.8 \mathrm{~ns}$ at $\mathrm{pH}$ 9.5. In comparison with the cytoplasmic SypHer3s, the dynamic range of SypHerExtra is lower. Such a difference could be explained by the limitations in measurements and data processing, as the resolution of the FLIM images is only 512 x 512 pixels; therefore, only the outer part of the cell membrane cannot be chosen as the region of interest (ROI) - there is also the SypHerExtra population located at the intracellular part of the membrane, and even some parts of cytoplasmic sensor that are taken into account during the fluorescence lifetime calculation. It is known that only extreme alkalinization $(\mathrm{pH}>8.5)$ could affect the intracellular $\mathrm{pH}$ [36]. This phenomenon was also observed in our data. For example, the treatment of cells with a buffer of $\mathrm{pH} 9.5$ resulted in an increase in the intracellular $\mathrm{pH}$ value to about $\mathrm{pH} 8.0$ (Figure S3G). Also, the differences in lifetimes can be explained by the existence of two populations of SypHerExtra-the "truly" extracellular one, which has a fluorescence lifetime corresponding to the buffer $\mathrm{pH}$, and another one that seems intracellular, which is located inside the cell endosomes and has a lower fluorescence lifetime related to the intracellular endosomal $\mathrm{pH}$. The resulting fluorescence lifetime for these two populations is lower than the SypHer3s fluorescence lifetime at the same $\mathrm{pH}$. Nevertheless, there is a strong $\mathrm{pH}$ dependence of fluorescence lifetime for both the cytoplasmic SypHer3s protein and the extracellular membrane-bound SypHerExtra sensor that allows intracellular and extracellular $\mathrm{pH}$ values to be measured in living cells by the FLIM method.

Supplementary Materials: The following are available online at https:/ / www.mdpi.com/article/10 .3390/bios11090340/s1, Figure S1: Fluorescent images of the fixed HeLa cells expressing SypHerExtra sensor, Figure S2. FLIM images of the nigericin-treated HEK293 cells expressing cytoplasmic SypHer3s sensor at different $\mathrm{pH}$ values: (A) $\mathrm{pH}$ 6.5; (B) $\mathrm{pH} 7.1$; (C) $\mathrm{pH} 7.5$; (D) $\mathrm{pH}$ 8.0; (E) $\mathrm{pH} 8.5$; (F) pH 9.0; (G) pH 9.5, Figure S3. FLIM images of the HEK293 cells expressing SypHerExtra sensor at different $\mathrm{pH}$ values: (A) $\mathrm{pH}$ 6.5; (B) $\mathrm{pH} 7.0$; (C) $\mathrm{pH} 7.5$; (D) $\mathrm{pH}$ 8.0; (E) $\mathrm{pH}$ 8.5; (F) $\mathrm{pH} 9.0$; (G) $\mathrm{pH}$ 9.5, Figure S4. Fluorescent images of the HEK293 cells expressing SypHerExtra sensor at $\mathrm{pH} 8.5$ (A) without nigericin and (B) after incubation with nigericin.

Author Contributions: Conceptualization: A.G.P., I.E.D., A.S.G. and A.A.P. Funding acquisition: A.A.P., I.E.D. and A.S.G. Investigation: A.S.G., A.A.P., A.V.R., I.D.R., E.G.M., A.N.O., O.V.S., A.A.M. and M.A.M. Resources: A.G.P., I.E.D. and A.S.G. Supervision: A.G.P. and I.E.D. Writing-original draft: A.S.G., A.A.P. and I.E.D. Writing-review and editing: A.S.G., A.A.P., A.V.R., I.D.R., E.G.M., A.N.O., O.V.S., A.A.M., M.A.M., V.I.M., I.E.D. and A.G.P. All authors have read and agreed to the published version of the manuscript.

Funding: This work was supported by the RFBR grants № 20-04-00880 and 19-34-51034. TCSPC experiments were carried out in frame of RSF grant № 19-73-20194. 
Acknowledgments: This work was carried out with the active support of the Center for Collective Use of Scientific Equipment No. 74834 "Technological and diagnostic center for the production, research and certification of micro and nanostructures" in GPI RAS". Authors also thank Polina Adamovskaya for her help in checking the English language in this manuscript.

Conflicts of Interest: The authors declare no conflict of interest.

\section{References}

1. Hamm, L.L.; Nakhoul, N.; Hering-Smith, K.S. Acid-base homeostasis. Clin. J. Am. Soc. Nephrol. 2015, 10, 2232-2242. [CrossRef] [PubMed]

2. Prasad, H.; Rao, R. Amyloid clearance defect in ApoE4 astrocytes is reversed by epigenetic correction of endosomal pH. Proc. Natl. Acad. Sci. USA 2018, 115, E6640-E6649. [CrossRef]

3. Webb, B.A.; Chimenti, M.; Jacobson, M.P.; Barber, D.L. Dysregulated pH: A perfect storm for cancer progression. Nat. Rev. Cancer 2011, 11, 671-677. [CrossRef] [PubMed]

4. Alfarouk, K.O.; Ahmed, S.B.M.; Ahmed, A.; Elliott, R.L.; Ibrahim, M.E.; Ali, H.S.; Wales, C.C.; Nourwali, I.; Aljarbou, A.N.; Bashir, A.H.H.; et al. The interplay of dysregulated $\mathrm{pH}$ and electrolyte imbalance in cancer. Cancers 2020, 12, 898. [CrossRef] [PubMed]

5. White, K.A.; Grillo-Hill, B.K.; Barber, D.L. Cancer cell behaviors mediated by dysregulated pH dynamics at a glance. J. Cell Sci. 2017, 130, 663-669. [CrossRef]

6. Bilodeau, J.; Désilets, A.; McDuff, F.-O.; St-Pierre, C.; Barbar, É; Leduc, R.; Lavigne, P. Influence of Ca ${ }^{2+}$ and $\mathrm{pH}$ on the folding of the prourotensin II precursor. FEBS Lett. 2011, 585, 1910-1914. [CrossRef]

7. Schmidt, W.K.; Moore, H.P. Ionic milieu controls the compartment-specific activation of pro-opiomelanocortin processing in AtT-20 cells. Mol. Biol. Cell 1995, 6, 1271-1285. [CrossRef] [PubMed]

8. Depaoli, M.R.; Bischof, H.; Eroglu, E.; Burgstaller, S.; Ramadani-Muja, J.; Rauter, T.; Schinagl, M.; Waldeck-Weiermair, M.; Hay, J.C.; Graier, W.F.; et al. Live cell imaging of signaling and metabolic activities. Pharmacol. Ther. 2019, 202, 98-119. [CrossRef]

9. Germond, A.; Fujita, H.; Ichimura, T.; Watanabe, T.M. Design and development of genetically encoded fluorescent sensors to monitor intracellular chemical and physical parameters. Biophys. Rev. 2016, 8, 121-138. [CrossRef]

10. Sanford, L.; Palmer, A. Chapter one-Recent advances in development of genetically encoded fluorescent sensors. Methods Enzymol. 2017, 589, 1-49. [PubMed]

11. Benčina, M. Illumination of the spatial order of intracellular $\mathrm{pH}$ by genetically encoded $\mathrm{pH}$-sensitive sensors. Sensors $\mathbf{2 0 1 3}, \mathbf{1 3}$, 16736-16758. [CrossRef]

12. Martynov, V.I.; Pakhomov, A.A.; Deyev, I.E.; Petrenko, A.G. Genetically encoded fluorescent indicators for live cell pH imaging. Biochim. Biophys. Acta Gen. Subj. 2018, 1862, 2924-2939. [CrossRef] [PubMed]

13. Hanson, G.T.; McAnaney, T.B.; Park, E.S.; Rendell, M.E.P.; Yarbrough, D.K.; Chu, S.; Xi, L.; Boxer, S.G.; Montrose, M.H.; Remington, S.J. Green fluorescent protein variants as ratiometric dual emission $\mathrm{pH}$ sensors. 1 . Structural characterization and preliminary application. Biochemistry 2002, 41, 15477-15488. [CrossRef]

14. Matlashov, M.E.; Bogdanova, Y.A.; Ermakova, G.V.; Mishina, N.M.; Ermakova, Y.G.; Nikitin, E.S.; Balaban, P.M.; Okabe, S.; Lukyanov, S.; Enikolopov, G.; et al. Fluorescent ratiometric $\mathrm{pH}$ indicator SypHer2: Applications in neuroscience and regenerative biology. Biochim. Biophys. Acta Gen. Subj. 2015, 1850, 2318-2328. [CrossRef] [PubMed]

15. Ermakova, Y.G.; Pak, V.V.; Bogdanova, Y.A.; Kotlobay, A.A.; Yampolsky, I.V.; Shokhina, A.G.; Panova, A.S.; Marygin, R.A.; Staroverov, D.B.; Bilan, D.S.; et al. SypHer3s: A genetically encoded fluorescent ratiometric probe with enhanced brightness and an improved dynamic range. Chem. Commun. 2018, 54, 2898-2901. [CrossRef] [PubMed]

16. Poburko, D.; Santo-Domingo, J.; Demaurex, N. Dynamic regulation of the mitochondrial proton gradient during cytosolic calcium elevations. J. Biol. Chem. 2011, 286, 11672-11684. [CrossRef]

17. Datta, R.; Heaster, T.M.; Sharick, J.T.; Gillette, A.A.; Skala, M.C. Fluorescence lifetime imaging microscopy: Fundamentals and advances in instrumentation, analysis, and applications. J. Biomed. Opt. 2020, 25, 1-43. [CrossRef]

18. Periasamy, A.; Mazumder, N.; Sun, Y.; Christopher, K.G.; Day, R.N. FRET microscopy: Basics, issues and advantages of FLIMFRET imaging. In Advanced Time - Correlated Single Photon Counting Applications; Becker, W., Ed.; Springer International Publishing: Cham, Switzerland, 2015; pp. 249-276. ISBN 978-3-319-14929-5.

19. Serova, O.V.; Radionov, N.V.; Shayahmetova, D.M.; Deyev, I.E.; Petrenko, A.G. Structural and functional analyses of the sixth site of neurexin alternative splicing. Dokl. Biochem. Biophys. 2015, 463, 239-242. [CrossRef]

20. Grillo-Hill, B.K.; Webb, B.A.; Barber, D.L. Ratiometric imaging of pH probes. Methods Cell Biol. 2014, 123, 429-448.

21. Adamson, P.; Paterson, H.F.; Hall, A. Intracellular localization of the P21rho proteins. J. Cell Biol. 1992, 119, 617-627. [CrossRef]

22. Diering, G.H.; Numata, M. Endosomal $\mathrm{pH}$ in neuronal signaling and synaptic transmission: $\mathrm{Role}$ of $\mathrm{Na}(+) / \mathrm{H}(+)$ exchanger NHE5. Front. Physiol. 2014, 4, 412. [CrossRef] [PubMed]

23. Thomas, J.A.; Buchsbaum, R.N.; Zimniak, A.; Racker, E. Intracellular pH measurements in Ehrlich ascites tumor cells utilizing spectroscopic probes generated in situ. Biochemistry 1979, 18, 2210-2218. [CrossRef]

24. Lin, H.-J.; Herman, P.; Lakowicz, J.R. Fluorescence lifetime-resolved pH imaging of living cells. Cytom. A 2003, 52, 77-89. [CrossRef] [PubMed]

25. Schwalfenberg, G.K. The alkaline diet: Is there evidence that an alkaline $\mathrm{pH}$ diet benefits health? J. Environ. Public Health 2012, 2012, 727630. [CrossRef] [PubMed] 
26. Serova, O.V.; Gantsova, E.A.; Deyev, I.E.; Petrenko, A.G. The value of $\mathrm{pH}$ sensors in maintaining homeostasis of the nervous system. Russ. J. Bioorg. Chem. 2020, 46, 506-519. [CrossRef]

27. Deyev, I.E.; Sohet, F.; Vassilenko, K.P.; Serova, O.V.; Popova, N.V.; Zozulya, S.A.; Burova, E.B.; Houillier, P.; Rzhevsky, D.I.; Berchatova, A.A.; et al. Insulin receptor-related receptor as an extracellular alkali sensor. Cell Metab. 2011, 13, 679-689. [CrossRef] [PubMed]

28. Serova, O.V.; Orsa, A.N.; Chachina, N.A.; Petrenko, A.G.; Deyev, I.E. c-Met receptor can be activated by extracellular alkaline medium. J. Recept. Signal Transduct. Res. 2019, 39, 67-72. [CrossRef]

29. Serova, O.V.; Chachina, N.A.; Gantsova, E.A.; Popova, N.V.; Petrenko, A.G.; Deyev, I.E. Autophosphorylation of orphan receptor ERBB2 can be induced by extracellular treatment with mildly alkaline media. Int. J. Mol. Sci. 2019, 20, 1515. [CrossRef]

30. Goryashchenko, A.S.; Mozhaev, A.A.; Serova, O.V.; Erokhina, T.N.; Orsa, A.N.; Deyev, I.E.; Petrenko, A.G. Probing structure and function of alkali sensor IRR with monoclonal antibodies. Biomolecules 2020, 10, 1060. [CrossRef] [PubMed]

31. Südhof, T.C. Neuroligins and neurexins link synaptic function to cognitive disease. Nature 2008, 455, 903-911. [CrossRef]

32. Carter, M.; Shieh, J. Microscopy. In Guide to Research Techniques in Neuroscience; Academic Press: Cambridge, MA, USA, 2015; pp. 117-144, ISBN 9780128005118.

33. Kobat, D.; Horton, N.G.; Xu, C. In vivo two-photon microscopy to 1.6-mm depth in mouse cortex. J. Biomed. Opt. 2011, 16, 106014. [CrossRef] [PubMed]

34. Takasaki, K.; Abbasi-Asl, R.; Waters, J. Superficial bound of the depth limit of two-photon imaging in mouse brain. Eneuro 2020, 7. [CrossRef] [PubMed]

35. Alim, I.; Haskew-Layton, R.E.; Aleyasin, H.; Guo, H.; Ratan, R.R. Spatial, temporal, and quantitative manipulation of intracellular hydrogen peroxide in cultured cells. Methods Enzymol. 2014, 547, 251-273. [PubMed]

36. Capellini, V.K.; Restini, C.B.A.; Bendhack, L.M.; Evora, P.R.B.; Celotto, A.C. The effect of extracellular pH changes on intracellular $\mathrm{pH}$ and nitric oxide concentration in endothelial and smooth muscle cells from rat aorta. PLoS ONE 2013, 8, e62887. 